\title{
HUMAN-CENTRIC TECHNOLOGY FOR URBAN PLANNING
}

\author{
Vaijayanthi Iyengar ${ }^{1}$ and Paul Chavez ${ }^{2}$ \\ ${ }^{1} 7$ Eleven, Director/UX, 13200 Hackberry Rd, Irving, TX 75063,, USA \\ ${ }^{2}$ Arup, Associate Technology/UX,. 900 Wilshire Boulevard, Los Angeles, California, USA
}

\begin{abstract}
When people gather, the space in which they meet has the potential to form bonds and create lasting communities. Successful urban spaces evolve structurally based on these communities, societal models, and the ability to coexist. With the evolution of smart and ubiquitous computing, spaces have a new variable that impacts social perception technology. In the past two decades, humans have evolved an intimate and everyday relation with digital technology. This article infers from studies on these performative relationships between humans and technology, it's behavioral manifestation and applies it to the current practices in urban development. The article also refers to a phase in the history of urban design where behavior-based people-oriented design gained momentum. The inferences from these two topics are used for making a case to formalize the process of inclusive technology in urban development so as to create a sustainable and resilient environment for urban denizens.
\end{abstract}

\section{KEYWORDS}

Citizen Engagement, Urban Perspective, Socio-Technical Challenges, Smart City Interaction

\section{INTRODUCTION}

This article is a collective output of exploratory discussions between a User Experience Designer and a Spatial Strategist. The discussion specifically focuses on two aspects: the 3rd paradigm of Human-computer interaction (Harrison, Tatar \& Sengers, 2007) and the impact of 1960s Behaviorism on urban development. While seemingly disparate, these two topics were explored together because they both fundamentally address the cultural and emotional aspects of considering humans in the design process. The 3rd paradigm of human-computer interaction, or: The Situated Paradigm, acknowledges the social, cultural, and physical situatedness of users in the context of digital technology. This helps to understand the behavioral aspirations of technology in humans and consequently in urban society. Historically, a similar momentum existed during the 1960s and 70s between behavior and spaces. During this era, the citizens and few urban designers questioned the monofunctional approach to architecture. A call for urban inclusion was made because the gap between the goals of urban residents and urban designers was widening. We discuss the manifestation of this historic movement into today's urban development processes and extrapolate some inferences into the future. The overarching goal of this effort is to identify the framework and theories that can be juxtaposed between urban planning and technology and therefore serve as the catalyst for a holistic design process for smart city planning.

\section{SITUATEDNESS IN HUMAN-COMPUTER INTERACTION}

Human-Computer Interaction could be informally classified in three paradigms: Human-Factors based, Classical Cognitivism/Information-Processing based, and the Third/Phenomenological-Situated paradigm based (Frauenberger, 2019). The third classification, which is an evidence-based developmental paradigm was of particular interest to our discussion since it elaborates on the concept of meaning-making. A comparable thought in urban design is termed "placemaking" (Thomas, 2016). Both concepts beseech the designers to create contextual artifacts based on the situation, collaborative inputs, socio-economic and 
psychological needs, and diversity in user/citizen requirements. In contemporary cities where political opinions are polarized, religion is an influencer, migration is debated, racial friction is heightened and the current pandemic is isolating, technology needs to be situational and emotional. This situatedness will encourage technologists to evolve operational algorithms for connected cities with non-tangible elements such as citizen psychology and other socio-tech factors. The ad hoc nature of digital networks is capable of supporting an adaptive urban space. The emerging technologies that are being applied for smart cities of the future should have the ability to respond to a fluid context. New modalities in technology like gestures, AR/VR, tangible/ non-tangible interfaces, and pervasive technology are often designed and applied in isolation (Bødker, 2006). The adaptive context of a space could be reflected in the modality of the chosen technology. For example, smart streetlights could be used to communicate the general health of a district using color-coded illumination.

\section{BEHAVIORISM OF THE 60S}

"The job of buildings is to improve human relations; architecture must ease them, not make them worse." Ralph Erskine

Around the early 60s as rapid urbanization happened across the major cities in the world, the modernist movement was gaining a lot of popularity among urban designers. 'Functionalism' is often characterized as the driving force for creating simplified, minimal spaces. This popular notion also emphasized creating negative spaces that often led to a "no man's land." While popular among urban designers for multiple decades from a human settlement perspective there was often a gap in addressing realities like social disparity, diversity and economic inclusivity (Forlano, 2009). Designers and urban inhabitants, with arguments that favored inclusion of people-centricity in urban design, later questioned these monofunctional approaches in design. They encouraged collective participation of citizens and designers to reinvent the definition of spaces, especially with focus on creating sustainable communities and shared values.

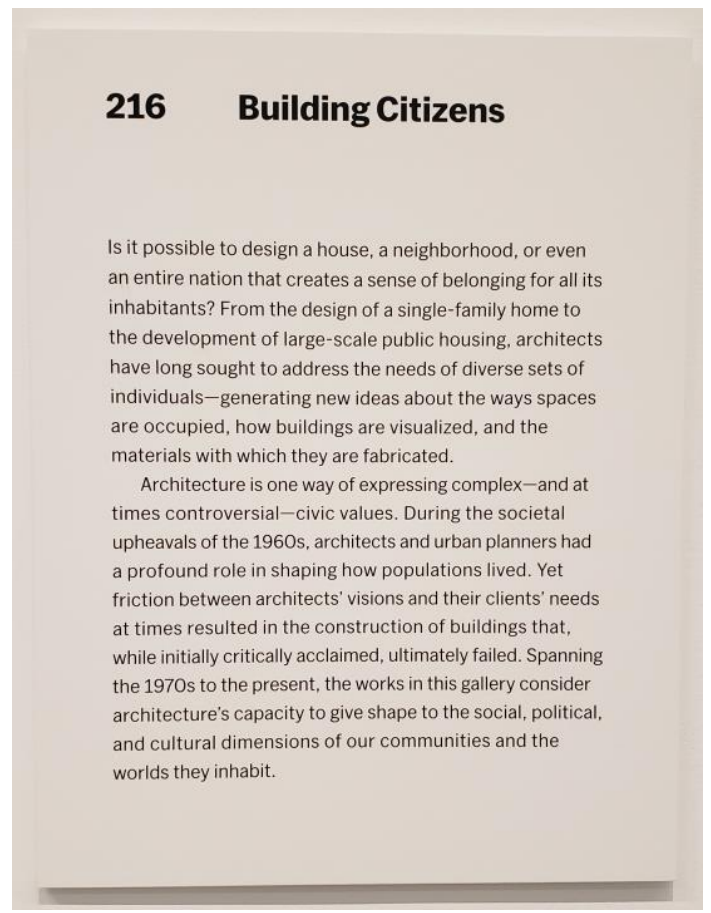

Figure 1. Exhibit 216 MoMA 
There was a demand for a platform to be heard and for their voices to be included in design decisions. The series of exhibits in the Museum of Modern Arts (MoMA), titled "Building Citizens" (Figure 1), one can view the struggle of social disruption in cities, gaps in layout, occupation of spaces, and even the visual language of buildings. This critical thinking invoked a sense of belonging while designing a home, neighborhood, or an entire nation.

The urban landscapes created during the $60 \mathrm{~s}$ and $70 \mathrm{~s}$ were labeled by some urban designers as "Behaviorism". The scholarly publications and urban design communities of this period often called out that urban settlements were failing owing to a gap between planners and residents. In her famous book, 'The Death and Life of Great American Cities', Jane Jacobs mentions the perils of modernist city planning, the rigidness of Functionalism, or rather the lack of people-sensitive insights (Sim, 2019). These observations were fueled by the ambiguities in pubic versus private space and the needs of its inhabitants. These gaps could be attributed to the fact that urban planners were designing with little, if any, input from the citizens. The changing viewpoints and perspectives led to a movement where the interaction between these factors were given greater importance and hence these decades marked the beginning of a very different phase of urban development.

\section{CURRENT SOCIO-TECHNICAL RELATIONSHIPS IN URBAN SPACES}

The systems that build a city are all not just physical entities. In fact, in his talk 'The Happy City Experiment', Charles Montgomery talks about how the parks, the roadways, the buildings, and the water bodies all contribute to the emotional infrastructure of a city. Similarly, the digital proliferation in transportation, commerce, waste disposal, communication, sheltering, health, and civic systems is also influencing this emotional infrastructure. Current technology trends are surpassing the needs of an individual and lending support for more connected community spaces. The networked nature of technology provisions liaising between the citizens, public infrastructure and urban developers. From the recent gatherings and conferences on emerging design systems (RSD8 Symposium, 2019), it is observed that dynamic ecosystems come together for an instance of time, contextual to an event or message, and peer produced through social media. To design for future cities grounded in the principles of resilience, collaboration and inclusion, the complexity of these systems should be considered in building solutions for 'connected' cities.

The proliferation of technology in the past twenty years has enabled citizens to be vocal about their needs in urban evolution. Ranging from casual park gatherings to the \#BLM movement, we can see how emotion through social media, texting, tweeting, etc. made its way to the streets and reflected the pulse of the time. The tweets, vlogging and multiple social media channels were associated with zip codes, demographics, and law and order infrastructure. While the digital technology enabled transmission of citizen emotions, this was a reactive platform. If the cities can be proactively prepared to facilitate citizen participation in an organized approach, it can help create meaningful collaborations that could lead to accountability.

The following table outlines some contemporary examples of how technology and urban spaces have reactively and proactively come together to define new experiences.

Table 1. Contemporary examples of technology in urban spaces

\begin{tabular}{|l|l|}
\hline \multicolumn{1}{|c|}{ Technology } & \multicolumn{1}{c|}{ Human Experience } \\
\hline Wayfinding in Airports & $\begin{array}{l}\text { Rideshare like Uber or Lyft - digital interaction within an app is defining the parking } \\
\text { needs, pedestrian circulation, and signage in a space. For example, most urban airports } \\
\text { now have designated zones to accommodate rideshare users. The introduction of this } \\
\text { new pick-up zone resulted in an additional requirement: guidance to get there. Hence the } \\
\text { traditional physical signage is being overlaid with digital counterparts like GPS aps and }\end{array}$ \\
$\begin{array}{l}\text { AR-based guidance apps for aiding circulation. In addition, the circulations paths of } \\
\text { pedestrians, traffic flow of pick up and drop vehicles, etc. have changed based on these } \\
\text { popular digital applications (Kim, Wang \& Han, 2015) }\end{array}$
\end{tabular}




\begin{tabular}{|l|l|}
\hline $\begin{array}{l}\text { Digital physical retail } \\
\text { stores }\end{array}$ & $\begin{array}{l}\text { Amazon Go retail - The rating and review in a web application transcend into a brick- } \\
\text { and-mortar store. These stores carry a highly curated selection of products from the top } \\
\text { categories across Amazon.com. Strategically based beacons \& sensors, app-based POS } \\
\text { systems and integration with biometrics all work to make this experience seamless (and } \\
\text { with little human services intervention). }\end{array}$ \\
\hline The wireless scooter & $\begin{array}{l}\text { Uber is developing robotic versions of the ubiquitous electric scooter to support micro- } \\
\text { mobility. This will have an impact on urban planning, road traffic control, safety hazard } \\
\text { and support, docking and charging requirements and correlation with pedestrian } \\
\text { circulation. This is an example of a new transport ecosystem enabled by IoT that in turn } \\
\text { impacts other infrastructures within a city. The layout of roads, dimensions for } \\
\text { circulation, anthropometric considerations are all possibly going to get modified by } \\
\text { these digitized vehicles. }\end{array}$ \\
\hline City as a platform (CaaS) & $\begin{array}{l}\text { London is working with tech companies to tackle urban challenges. Widely addressed } \\
\text { topics included homelessness, social care, cyber-security, diversity, and inclusion. Tech } \\
\text { companies are developing the City as a platform strategy to create a more modular and } \\
\text { sustainable approach to smart cities. This approach will help to address the layers of } \\
\text { complexity in a city and aims to identify drivers necessary for change }\end{array}$ \\
\hline
\end{tabular}

\section{AREAS TO EXPLORE AND IMPROVE}

Based on the hypothesis drawn from an important phase of urban development and emerging paradigms in the HCI community, we conclude that technology can play an immersive role in the future of city planning. The gaps identified from urban development movements of the $60 \mathrm{~s}$ and $70 \mathrm{~s}$ reflect that built forms need to consider individual and societal needs including diversity, inclusivity and resiliency. Leading architectural journals like World Health Design, Environment Behavior, and HERD, have voiced that consciously designed spaces can influence behavior. Technology can facilitate emotional liaising between city planners and its dwellers on subjects that lend social, political, and cultural dimensions to space. Here are suggestions for Human-Centered Technology in urban planning

- Identification of tangible and intangible drivers that impact spatial aspirations

- Utilize big data to create metrics based on public trust, user acceptance, and citizen engagement in smart services. Intangibles like societal conflicts, fear, compatibility, well-being, hopefulness, empathy and tangibles like air quality, proximity, waste management

- Track behavior changes led by the daily usage of smart city services and facilities

- Trace and correlate emotional quotient and well-being related to an event or incident impacting the community

- Document socio-technical and systemic design industry challenges that impact the development and deployment of smart infrastructure in cities like smart mobility and waste management

- Provide dynamic and real-time channels to maintain transparency with citizens

- Identify touch points between technology and transitional environments - Transitions from home to vehicular environment, to a productive environment or commuting for leisure, the transition from work to recreation area

- Creating balances the automation systems that is tailored based on social context and real-time demographics

Today technology mostly exists in execution and realization capacity. In execution modes, technology often focuses on efficiency and productivity. This task-based process usually results in a capsule solution overlaid on traditional elements of urban architecture (e.g. buildings, streets, signage, lights, etc.).

In contemporary smart city solutions, the success is measured in terms of productivity and efficiency. But we fail to evaluate intangible factors, for example trust, fear and timelessness. To elaborate the impact of trust and fear in a smart city project we can take the example of the City of San Diego's Smart Streetlight program: While this program addresses energy efficiency, traffic congestion issues, IoT based crime tracking, it has also caused unrest in terms of unrestricted data mining triggering a fear of panopticism and prompting 
the question, "How can the data being acquired be more transparent and visible to citizens?" the artifacts installed and maintained by civic and urban development bodies can have a perception based context (Hargrove, 2019). These designs may have missed to consider that with passage of time citizens will interact with these urban elements in their everyday lives. And everyday interactions include political and emotional opinions.

This correlation technology, emotions and politics was observed early by Winner where he wrote that technical artifacts have political properties and in turn can embody forms of authority and subordination (Winner, 1980). Timelessness is another intangible factor for technology-based design consideration. Networked devices, digital displays, and audio systems do not have life spans that compare with street signs and lampposts. This requires planners and technologists to plan cities together in ways that allow for a high level of infrastructure flexibility where technologies may be added or updated. The mode of technology is merely a delivery system; however, the messaging is eternal. Inferences drawn from history (section 2 of this reflection) reflect that the concerns of citizens are more or less similar. Fifty years later, there are still divides, tensions and conflicts that great cities have to face and resolve. Through immersive technology, the citizen concerns get a collaborative platform, an amplified medium and an effective way of documenting actions and emotions.

\section{CONCLUSION}

Technology has been an important part of city planning of the past decade and modern cities have taken many steps to integrate technology. Urban planners are drifting from rigid guidelines of zoning into creating a human-centered urban design. Appointing CTOs, CIOs and CXOs of cities, partnering with innovative tech companies, and creating digital touch points for citizen engagement and participation are some examples.

Urban development and design are historically associated with architecture and hence have deep rooted connections with aesthetic theories of design and ingrained design practices. For the principles of human computer interaction design to be adopted for urban development, it is important to acknowledge the pockets of ad-hoc ecosystems that technology helps to create. Similarly, technologists designing for 'smart cities' also need to look beyond efficiency and productivity and take accountability to address the socio-economic and psychological aspirations of citizens. A technology solution to a human problem requires that human considerations are at the forefront of any technology application.

Cities outlive technology, so while the mode of technology might keep changing, the citizen's voices change slowly. In this information age of vloggers, bloggers, tweeters, and YouTubers, we have numerous channels to amplify their voice and the designers better be listening.

\section{REFERENCES}

Bødker, Susanne. (2006). When second wave HCI meets third wave challenges. ACM International Conference Proceeding Series. 189. 1-8. 10.1145/1182475.1182476.

Forlano, Laura. (2016). "Decentering the Human in the Design of Collaborative Cities." Design Issues 32, no. 3: 42-54.

Frauenberger C. (2019). "Entanglement HCI The Next Wave?" ACM Transactions on Computer-Human Interaction (TOCHI) 27: 2.

Hargrove Dorian. (2019, December 13). City Is Hiding Data From Smart Street Lights, https://www.nbcsandiego.com/news/local/city-is-hiding-data-from-smart-street-lights-lawsuit-claims/2230490/

Harrison, S. Tatar, D. and Sengers, P. (2007) The three paradigms of HCI. Ext. Abstracts CHI 2007, ACM Press

Kim, M., Wang, X., Han, S. et al. (2015). Implementing an augmented reality-enabled wayfinding system through studying user experience and requirements in complex environments. Vis. in Eng. 3, 14 https://doi.org/10.1186/s40327-015-0026-2

RSD8 Symposium. (2019, October 13-15). IIT Institute of Design, Chicago

Sim, David. (2019). Soft City: Building Density for Everyday Life, Island Press

Thomas, D. (2016). Placemaking: An Urban Design Methodology. Routledge.

Winner, Langdon. (1980). "Do Artifacts Have Politics?" www.jstor.org/stable/20024652. 